\title{
Competencias docentes ante la parálisis cerebral espástica
}

\author{
Carmen Lorena Armendáriz Vázquez \\ Escuela Normal Superior del Estado de Chihuahua \\ loremom_68@hotmail.com
}

\begin{abstract}
Resumen
El trabajo que a continuación se describe es producto de tesis doctoral concluida en torno al análisis de diferentes tipos de práctica docente; cuyo análisis aporta elementos suficientes para plantear y describir las necesidades de innovación al currículo de la Licenciatura en educación secundaria Plan 99, en beneficio del desarrollo de competencias docentes centradas en la atención de alumnos con barreras para el aprendizaje, principalmente asociados a parálisis cerebral espástica. Un profundo análisis del estado del arte que gira en torno a la atención de la parálisis cerebral espástica al interior de las aulas de la escuela regular muestra que son múltiples y enriquecedoras las indagaciones al respecto, que aunado a la obtención de datos proporcionados por informantes relacionados directamente con el objeto de estudio, ponen de manifiesto las competencias docentes que se requieren para la atención de alumnos con espasticidad. Para lo anterior se diseñó una indagación de corte Cualitativo por medio de un Estudio de caso con la utilización de técnicas como: observación directa, entrevista cara a cara, historia de vida e historia oral y grupo focal a informantes que viven o han vivido de cerca prácticas docentes centradas en la atención de la parálisis cerebral espástica como principal barrera de aprendizaje. En análisis de resultados expone claramente las modificaciones, e incorporaciones específicas que deben considerarse a corto plazo en el Plan de estudios 1999 de la Licenciatura en educación secundaria; específicamente en aspectos clave del Perfil de egreso y en algunas de las asignaturas; y en las orientaciones didácticas para los formadores de docentes; de tal forma que se garantice que los docentes en formación egresen con la competencias de respaldo adicional que les permita la atención profesional de este tipo de alumnos.
\end{abstract}

\section{Palabras clave}

Parálisis cerebral, espasticidad, formación docente, competencias docentes, educación secundaria.

\section{Introducción}

La atención que se oferta en Educación Especial en México cuenta ya con más de ciento cincuenta años, este recuento se menciona en el Programa de desarrollo educativo 1995-2000, explicando que durante el gobierno Juarista se expidieron los decretos que dieron origen a la fundación de la Escuela Nacional para Sordomudos en 1867, y la Escuela para Ciegos en 1870; a principios de siglo XX se funda el Instituto Médico Pedagógico del cual surgió la primera Normal de Especialización. De igual forma se menciona que, ante las necesidades de la 
época, en 1950 se crea el Instituto de Rehabilitación para Niños Ciegos. Conformando de este modo el grupo de instituciones pioneras de los procesos de integración al desarrollo social de alumnos que presentan necesidades educativas especiales (nee) y barreras para el aprendizaje asociadas a discapacidad.

Las acciones enunciadas permitieron que lo que ahora se conoce como Educación especial consolide su funcionamiento como uno de los sub-niveles de educación básica, que presta sus servicios en el estado de Chihuahua desde hace más de veinte años. En este sentido, las decisiones de política educativa, se fundamentan en la filosofía de la educación y en los derechos humanos universales; de igual forma en las sugerencias y recomendaciones posteriores a evaluaciones del Sistema educativo nacional mexicano realizadas por organismos internacionales como la OCDE.

Varios de los principios pedagógicos que sustentan en actual Plan de estudios para la educación básica, reconoce que el docente de este momento educativo, requiere entre otros aspectos una práctica docente que logre: centrar la atención en los estudiantes y en sus procesos de aprendizaje; planificar para potenciar el aprendizaje; generar ambientes de aprendizaje; trabajar en colaboración; desarrollar competencias: evaluar para aprender y favorecer la inclusión para atender la diversidad.

Atender los enfoques y las indicaciones técnico-pedagógicas planteados en el Plan de estudios 2011 hace imprescindible la presencia de un docente que ostente una preparación profesional más allá de lo que actualmente está considerado en la currícula de respaldo que cursaron docentes que prestan sus servicios en la educación secundaria; ya que se deben movilizar competencias profesionales no desarrolladas en su formación; que les permitan la atención especializada y de calidad a una amplia variedad de necesidades presentes en sus alumnos.

Es por ello que este trabajo se centra en identificar:

¿Cuáles competencias docentes deben favorecerse para eficientar la atención de los alumnos de educación secundaria con barreras para el aprendizaje centradas en la parálisis cerebral espástica?

De tal manera que el principal objetivo es:

Exponer diferentes prácticas docentes actuales para plantear y describir las necesidades de innovación al currículo de la Licenciatura en educación secundaria Plan 99, en beneficio de una formación docente que desarrolle competencias para la atención de alumnos con necesidades especiales asociados a parálisis cerebral espástica.

\section{Marco conceptual}

La actual administración federal ha permitido en este país el desarrollo de una política pública que se anuncia con la intención de procurar la elevación de la calidad educativa, por ello se han articulado los principales niveles educativos en lo que se actualmente se conoce como educación básica, sin embargo, se hace necesario precisar que durante la educación secundaria o bien durante el 4 o periodo escolar del actual mapa curricular, existen adolescentes con características muy específicas que marcan la diferencia en la atención que requieren y esa variable se acentúa al incluir casos de parálisis cerebral espástica con características adicionales de cuadriplejia, con los cuales, también se hace necesario orientar el trabajo diario en el logro de los aprendizajes y los Estándares curriculares de tal forma que se consolide en el mayor porcentaje posible de los rasgos enunciados en el perfil de egreso de la Educación Básica. 
La significación de los alumnos en mención requiere de puntualizaciones como las de Sánchez, Botías e Higueras (2002:235) quienes consideran que la parálisis cerebral es un "Desorden permanente y no inmutable de la postura y el movimiento debido a una lesión del cerebro antes de que desarrollo y el crecimiento sean completos". Para Atkinson (1998:356) la Parálisis Cerebral obedece a una lesión o funcionamiento anómalo del sistema nervioso central en el lactante o niño pequeño, que se caracteriza por posturas y movimientos anormales, además de alteraciones en el tono muscular. Refiere también, que ésta puede ser congénita o adquirida $y$ sus diferentes causas son identificadas como: Agenesia o desarrollo defectuoso de las neuronas. y/o lesión encefálica o deterioro de las neuronas intracraneales por nutrición defectuosa del encéfalo la cual puede suceder antes, durante y después del parto.

A partir de las causas identificadas anteriormente; Atkinson (1998) explica que la parálisis cerebral dará lugar a diferentes formas de manifestación conocidas como diplejía, triplejia, paraplejia, hemiplejia, monoplejia y cuadriplejia en la cual se ven afectados los cuatro miembros y severamente desaparece un control voluntario del cuello del afectado, por lo que requieren de diferente tratamiento desde el punto de vista educativo.

Además de la clasificación anterior la parálisis cerebral se puede clasificar (según las coincidencias expresadas por Bobaht en el año 1997 y las de Atkinson en 1998) por la capacidad de movimiento que se tiene y dicha clasificación se encuentra definida en: Atetosia, Ataxia y Espasticidad, que se caracteriza por un aumento de tono generalizado donde prácticamente se llega a la rigidez o a la tensión y se puede apreciar tanto en músculos flexores como extensores, dependiendo de la postura que se adopte, además presenta patrones primitivos patológicos y según se experimenta pueden ir fácilmente de la hipotonía a la hipertonía.

Unidos entonces los términos de cuadriplejia y espasticidad (Bobaht, 1997) el cuadro es desalentador, principalmente porque en estos casos la comunicación se torna un elemento muy significativo para el alumno ya que debido a su restringida movilidad, depende en gran medida de que las personas que están a su alrededor le comprendan para satisfacerle lo que necesita, asimismo por la necesidad natural de pertenecer a un grupo, le es esencial estar comunicado, aunado a su interés de consolidar su educación básica.

En ese sentido, la práctica docente que este país exige de los docentes que laboran en Educación Básica, debe ser inclusiva a partir de crear escenarios áulicos fundamentados en los derechos humanos y el respeto a la dignidad humana, de tal forma que cada uno de los alumnos, independientemente de sus condiciones desarrolle sus habilidades $y$ competencias intelectuales, sociales, emocionales y físicas.

Además, es imprescindible que los docentes sean empáticos con una cultura actual y diferente de desarrollar su tarea diaria y de igual forma con las necesidades de los alumnos que pueden ser distintas a sus concepciones. Entendiendo que la inclusión real requiere de estrategias de aprendizaje y enseñanza diferenciadas, observando $\mathrm{y}$ salvando las barreras para el aprendizaje con el fin de promover y ampliar, en la escuela y las aulas, oportunidades de aprendizaje, accesibilidad, participación, autonomía y confianza en sí mismos, ayudando con ello a combatir actitudes de discriminación.

\section{Método}

La utilización del enfoque cualitativo se define a partir de identificar que "proporciona descripciones detalladas de situaciones, eventos, personas, interacciones y comportamientos que son observables, 
incorporando la voz de los participantes, sus experiencias, actitudes, creencias, pensamientos y reflexiones tal y como son expresados por ellos mismos". (Sandín, 2003:121) de ahí, que una vez seleccionado el método y las técnicas e instrumentos puede ser analizada en su totalidad la realidad en estudio.

La utilización de la investigación cualitativa y la selección del estudio caso como método principal de investigación se da, inicialmente; en función de que según Stake (1995) existen variados principios teóricos de la investigación cualitativa presentes en el estudio de casos, que a su vez constituyen un conjunto de métodos de investigación de carácter naturalista, holístico, fenomenológico, etnográfico y biográfico; que a su vez permitieron bajo una dimensión analítica e interpretativa y dentro de lo que se puede llamar: una visión retrospectiva de las escalas de valores, la identificación de los compromisos, actitudes y necesidades formativas en torno a la parálisis cerebral de los docentes.

La concreción del estudio de caso se pudo construir a partir de participar de observaciones concretas, realizar entrevistas cara a cara, y de documentar historias de vida e historias orales a los principales informantes en torno a la identificación de las características de la práctica docente que da respuesta efectiva a los requerimientos de la parálisis cerebral en alumnos de secundaria.

\section{Resultados}

Los docentes requieren actualización, capacitación y formación profesional

Para lograr interpretar las razones que tienen los docentes de apoyo para actuar o realizar ciertas acciones ante la atención de las necesidades educativas especiales asociadas a secuelas de parálisis cerebral espástica se hace necesario retomar lo expresado por Ardiles (2005) cuando menciona que la capacitación y actualización de docentes es la creación institucional de espacios de trabajo académico que permiten a los profesores recuperar sus saberes y prácticas, ponerse en contacto con los de otros y conocer o reconocer nuevos aspectos de la práctica docente con lo cual los maestros están en posibilidades de desarrollar más eficazmente su labor.

Se entiende entonces que lo anterior, indudablemente puede ser tomado como un sinónimo de perfeccionamiento docente que al realizarse debe ser fundamentado en una estrategia de cambio educativo que imprime reflexión educativa; esta reflexión educativa que permite actualizar y capacitar docentes viene a subsanar las debilidades provenientes de una formación docente no suficiente para las tareas educativas a desarrollar.

"No debemos olvidar que el docente basa su profesionalidad en un conjunto de conocimientos adquiridos a través de su formación y experiencia práctica y además en el desarrollo de aquellas aptitudes personales que mejor puede poner en juego en su tarea de estimular el progreso de los alumnos que atiende". (Puigdellivol: 2007).

\section{Normativa técnico-pedagógica de apoyo}

$\mathrm{Al}$ analizar en significado de normativa en el contexto educativo es posible identificar que se refiere a todo lo relacionado con indicaciones técnico-pedagógicas que deben ser atendidas por los docentes al frente de los grupos en la educación básica. "un lineamiento es una tendencia, una dirección o rasgo característico que indica las normas técnicas que han seguirse para llevar a cabo la tarea educativa; se trata de un conjunto de medidas, normas y objetivos, que se encuentran en sintonía con las finalidades de la educación".

Cuando los docentes analizan los escasos contenidos a los que han tenido 
acceso y que les indican cual debe ser su función en atención a los lineamientos normativos se encuentra que mencionan situaciones como las siguientes: ORT4 "quisiera que alguien me explique porque el personal de educación especial no tiene más de tres documentos que nos permiten conducir nuestro trabajo" refiriéndose a los diferentes documentos de carácter normativo no conocidos ni aplicados por todos.

\section{Atención específica}

La 4a línea de acción del Programa de Fortalecimiento a la educación especial y de la integración educativa marca claramente que una de las principales tareas de esta programa es: "Garantizar que el personal de educación especial, educación inicial y básica cuente con las competencias necesarias y el compromiso ético para atender eficazmente a los alumnos con necesidades educativas especiales, prioritariamente a los que presenten alguna discapacidad".

Por ello, se puede iniciar por mencionar variadas opiniones que reconocen abiertamente el desconocimiento por múltiples razones de las formas de diseñar los tratamientos específicos de ahí que en el CDA3 se reconoce, "yo creí que en educación especial iba a trabajar con niños con problemas de aprendizaje ya que de algún modo, si me prepararon para ello en la normal; no me pasó por la mente trabajar con niños con alguna discapacidad".

Incluso se intenta explicar que solamente se hace una parte de la tarea educativa al expresar que CDA1 "lo que se hace con ellos está más encaminado a que aprendan contenidos y quienes no sabemos dejamos de lado lo medular, que es la atención específica de su discapacidad"; la crítica al sistema no se hace esperar y se dice CDR6 " $¿$ en qué momento se considera que un docente normalista puede dar atención especializada a alumnos que requieren conocer del funcionamiento y atención de músculos dañados?".

\section{Organización interinstitucional}

Los datos empíricos muestran una realidad de la zona escolar en estudio no congruente en muchas de las ocasiones con lo que se entiende por trabajo colaborativo, lo que inicialmente queda demostrado durante las observaciones realizadas a una de las sesiones de capacitación, OSC1donde se expresa “¿Para usted cuáles son las razones por las cuales no existe comunicación efectiva entre las USAER que atienden secundaria por las cuales no todos trabajamos de la misma forma".

Los asistentes de las reuniones con carácter de técnico-pedagógicas tratan de buscar las formas de solucionar las faltas de organización que perciben y expresan: OSC1 "con lo avanzado que están las cosas en educación especial sería muy benéfico que organizáramos o diseñáramos algún plan de trabajo local que nos facilite el trabajo diario con los docentes de las primarias en cuanto a atención"; OSC1 "de hecho la organización debe existir, sin duda que incluyendo a los personales completos de las escuelas regulares con los que trabajamos a diario"; y conocen tan bien la realidad y la falta de organización que hubo un momento en el que alguien se dio cuenta de que OSC1 "nadie escucha al personal regular cuando dice que necesitamos estar cerca de ellos para llevar a cabo las acciones en conjunto y con objetivos comunes".

Se percibe que la necesidad que los docentes expresan no es algo que mencionen solo por buscar algo para estar en contra del sistema; de igual forma, no queda claro si para ellos esta necesidad de trabajo colaborativo está fundamentada en alguna indicación o lineamiento técnico o de carácter teórico; sin embargo, la consulta a los expertos hace válidos sus reclamos ya que desde 1981, Toledo, ha expresado que para llevar a un alumno con necesidades educativas 
especiales a la escuela regular, se hace necesario atender algunas líneas generales que lleven a la ejecución de un plan que permita realizar con éxito esta encomienda.

\section{La imagen del docente ante sí mismo}

La categoría final que se muestra permite definir claramente la situación en que los docentes participantes de esta investigación se ven a sí mismos; la utilidad de esta categoría estriba en el reconocimiento de las razones de algunas de sus acciones; acertadas o no tan acertadas pero muchas de ellas tiene un argumento fuerte; EFD1 "tengo toda la voluntad del mundo pero en realidad atender a estos niños sobrepasa mis conocimientos, yo salí de una normal en la que no nos preparaban para atenderlos y no me gusta simular que si se y solo tenerlos en mi salón".

\section{Discusión y conclusiones}

La interpretación de los datos anteriores hace inminente la innovación y actualización a corto plazo del Plan de estudios de la Licenciatura en educación secundaria 1999 a partir de las siguientes incorporaciones.

\section{En el Perfil de egreso}

Aspecto referente al dominio de los propósitos y los contenidos de la educación secundaria, se requiere que además se dominen los tipos de adecuaciones existentes para la atención de las diferentes necesidades educativas especiales.

En cuanto a competencias didácticas se requiere que el docente diseñe las adecuaciones al currículo y plan de clase conforme a la necesidad específica de igual forma que conozca, seleccione y domine la implementación de los materiales que cada necesidad específica necesita.

En Identidad profesional y ética es necesario que se identifique como un agente de cambio social que asume la responsabilidad de promover escuelas inclusivas.

En lo referente a capacidad de percepción y respuesta a las condiciones sociales del entorno de la escuela se hace imprescindible que el docente procure favorecer un cambio de cultura en beneficio de la atención la eliminación de barreras para el aprendizaje.

En el apartado de Criterios y orientaciones para la organización de las actividades académicas es conveniente incorporar acciones específicas en cada asignatura del Plan 1999, que orienten a los formadores de docentes en la incorporación paulatina de las indicaciones que se precisan en los principios pedagógicos del plan de estudios 2011.

\section{En las asignaturas}

La asignatura de Propósitos y contenidos de la educación básica debe ser actualizada y atender el estudio y análisis reflexivo del Plan de estudios 2011 para la Educación básica, donde se prevee la atención efectiva de las necesidades educativas de aprendizaje.

La correspondiente al desarrollo del adolescente debe también además de actualizar el contenido vigente, ampliar el campo de estudio e incluir el desarrollo de los adolescentes atendiendo al conocimiento y análisis de las diferentes discapacidades y/o barreras de aprendizaje.

La asignatura de Gestión escolar requiere actualizar sus contenidos en pro de incorporar los fundamentos del Liderazgo estratégico que impera en este momento educativo a fin de que los docentes en formación privilegien entre otros aspectos no menos importantes; la colaboración entre iguales que requieren para la atención de las necesidades educativas especiales.

En los cursos sobre Observación y Práctica Docente y los de Planeación de la Enseñanza y Evaluación del Aprendizaje se 
hace imprescindible la integración del enfoque por competencias para el análisis profundo de la realidad y la simultánea reflexión en torno a las teorías que respaldan este modelo educativo en la educación secundaria.

En las asignaturas de cada una de las especialidades se requiere incorporar de manera práctica la presencia de las adecuaciones curriculares dependiendo de la atención a las necesidades específicas.

\section{Referencias}

Ardiles Martha., (2005). El desarrollo profesional de los docentes de la escuela media. Experiencias y aprendizajes cotidianos. Córdoba:editorial Brujas

Atkinson W. Hellen. (1998). Neurología para fisioterapeutas, Trillas: México.

Bobaht Bertha y Bobath Karel. (1997).Desarrollo motor en los distintos tipos de parálisis cerebral. Argentina:Editorial Médica Panamericana.

Puigdellivol I., (2007). La educación especial en la escuela integrada: una perspectiva desde la diversidad. Barcelona: Grao.

Sánchez C. J, Botías P. F., Higueras E A., (2002) Supuestos prácticos de Educación Especial. 4oㅜ reimpresión.

Sandín, M. P. (2003). Investigación cualitativa en educación; Fundamentos y tradiciones. España:Mc Graw Hil

Secretaría de Educación Pública. (2002). Programa Nacional de Fortalecimiento de la Educación Especial y de la Integración Educativa. México:Taller de libros de texto gratuitos.

Stake, R.E. (1995). Investigación con estudio de casos, $3^{\underline{a}}$ ed., Ediciones Morata, ISBN 978-84-7112-422-7

Yin, R. K. (1993). Applications of case sudy reaserch Newbury Park, CA: Sage. 
RECIE. Revista Electrónica Científica de Investigación Educativa Vol. 1, núm. 2, enero-diciembre 2013, pp. 359-365. 